\title{
Secondary Suicide Prevention as Neuro-Rehabilitation
}

\section{Valach Ladislav}

Private practice, Burgdorf, Switzerland

"Corresponding Author: Dr. Valach Ladislav, Lindenstrasse 26, 3047 Berne, Switzerland, Tel: +41792162192; Email: ladislav.valach@swissonline.ch

Received: 10 January 2018; Accepted: 19 January 2018; Published: 22 January 2018

\begin{abstract}
Neuro-rehabilitation and suicide prevention used to be linked together mostly as preventing suicidality in neurorehabilitation patients after, e.g., brain injury. However, we propose that the recent changes in neuro-rehabilitation, on the one hand, and in the suicide conceptualization, on the other, suggest the possibility of using some of the principles of neuro-rehabilitation in suicide prevention. The changes in neuro-rehabilitation include the integration of cognitive processes in motor processes [1,2] and stressing the bottom-up in contrast to top-down procedures suggested by cognitive behavioral therapy. The changes in suicide conceptualization include the view of suicide as a distorted goal-directed action. The secondary suicide prevention procedure linked equally to neuro-rehabilitation as to psychotherapy is a consequent conceptualization of this process as a joint goal-directed action and project, using the video self-confrontation as an action experiencing procedure including mentalizing [3] and the video-selfconfrontation with the integration of alternative action and action steps to revise the target actions and project [4]. Finally, a reminder in the form of a postal nudge to follow the joint life-enhancing project rounds up the secondary suicide preventive procedure. The development of professional and scientific disciplines, as well as treatment and health services is driven by their contribution to the target aims, but it also is a social process with its own institutions and professional identities that sometimes hinder a cross disciplinary fertilization. We would like to suggest that we should consider enriching the secondary suicide prevention by neuro-rehabilitation. This crossfertilization becomes meaningful when we acknowledge the changes in each discipline. Thus, we briefly outline some of the changes in neuro-rehabilitation, in the suicide conceptualization, and in secondary suicide prevention before summarizing the secondary suicide prevention procedure encompassing some of the neuro-rehabilitation views.
\end{abstract}

Keywords: Neuro-rehabilitation; Cognitive processes; Motor behavior; Suicide prevention 


\section{Neuro-Rehabilitation and its Recent Developments}

Neuro-rehabilitation is a professional discipline with evidenced procedures helping patients, e.g., after brain injury to improve their everyday functioning [5]. Traditionally, it was the physical therapy and the physical therapy professionals covering the neuro-rehabilitation tasks in inpatient and outpatient settings [6]. Recently, the recognition that incorporating cognitive processes might support the rehabilitation efforts to improve everyday functioning led to new understanding of the motor behavior [7-9]. Thus, the motor action was conceptualized in a more comprehensive way [10-12]. Equally, it has been recognized that the inclusion of cognitive processes in rehabilitation cannot be achieved by adopting the principles of cognitive-behavioral psychotherapy, as these relied too much on top-down instructions that did not always prove efficient [13]. Cognitive-behavioral psychology suggested that clear thinking led to effective behavior. Meichenbaum [14] reported that a group of people with organic dysfunction (attention deficit disorder) could improve their behavior self-regulation by learning goaldirected self-talk. One of the basic premises of cognitive rehabilitation was that relearning how to remember and how to regulate attention and behavior through internal verbalizations should greatly improve patient's adjustment after brain injury.

The effective procedures included cognitive action processes in motor behavior and stressed the experiential nature of the rehabilitative actions [15]. During rhythmic foot or leg movements the primary motor cortex is activated, and during movement preparation and anticipation frontal and association areas are activated [16]. Cognitive function is importantly related to successful rehabilitation. Poorer attention performances are associated with a more negative impact of stroke disability on daily functioning [17].

All these attempts were based on the contemporary knowledge of brain plasticity $[18,19]$ and on developing brain structures later in life that can take over the functions affected or distorted by a brain injury [20]. The question is sometimes posed, whether the brain training should be thought of as an alternative to traditional psychotherapeutic techniques or as complementary approaches [21]. However, despite some research evidence about learning through observing or imagining that is often equal to learning by performing the target activity [22, 23], the evidence of cognitive rehabilitation of executive functions needs additional support [24, 25]. A meta-analysis of cognitive rehabilitation literature revealed sufficient evidence for the effectiveness of attention training after traumatic brain injury and of language and visuospatial training for aphasia and neglect syndromes after stroke [26]. The recent development in rehabilitation and particularly neuro-rehabilitation taught us an active approach [27]. It has been suggested that physical training improves survival rates after myocardial infarction [28]. Thus the traditional resting approach became obsolete. Equally, the current neuro-rehabilitation practice relies on neuroplasticity and promotes intensive use of the affected side in motor deficits after a neurological event [29]. Consequently, the compensatory approach is losing grounds. Similarly, in suicide prevention the attempt to strip the suicide behavior of its intentionality proved to be a cul-de-sac in suicide prevention. Neither the lifting of the goal-directedness of the suicide process ("it was an illness not you causing this behavior"), nor implying that this intentionality is intact ("nosuicide-contract") proved to be an effective path to suicide prevention. 


\section{Suicide Conceptualization and the Conception of Suicide as a Distorted Goal-Directed Action}

Discussing suicide prevention in context of neuro-rehabilitation requires some explanation. Obviously, dealing with the personal consequences of brain injury the issue of depression, suicidality, posttraumatic stress disorder and many other linked neuro-rehabilitation and suicide prevention [30]. However, this is not the cross-fertilization we intent to address here. Secondary suicide prevention is usually performed within classical psychotherapy and by various psychotherapy schools, such as psychodynamic, cognitive-behavioral psychotherapy, experiential-emotion therapy, dialectic behavioral therapy and many others [31,32]. The recognition that suicide is not a moral issue led to the inclusion of suicidality in mental health classifications and thus to the conceptualization of suicide as an illness. As such and its strong link to depression led to an approach to suicide prevention with a somewhat limited success [33]. Unlike other mental health problems, suicidality is defined by a specific event, behavior, thoughts and emotions, which fall within the concept of action.

We proposed Michel et al. [34] that while the recognition that a suicidal person requires help, support, and protection is correct, it is also necessary not to strip such persons of their intentionality and goal-directedness, however mislead and destructive. We suggested that suicide should be conceptualized in action terms and we illustrated the processes of suicidal goal-directed action, suicide project and career. We maintained further that suicide is a distorted goal-directed action [35]. The main distortion indicated in the narrative of suicidal patients can be found in the disconnect among the wish to die, the action of killing, and the experience of being killed.

In the utterances on wanting to die, the patients expressed a disconnection from long-term pursuits, such as the goal to die and other, life-enhancing careers. Patients described experiencing suicidal situations as existentially threatening indicating that emotional memory (an experience from childhood) replaced the usual emotional monitoring. They also considered the option of taking one's own life as the last resort in a context that would seem conventional to others, which we qualified as a problem of action distortion. Further, the patients indicated a discrepancy between intention and action; persons were engaging in an action that would be defined by the majority of observers as a suicidal action without reporting to hold a firm suicidal intention for this act. There also was a severance apparent between a long-term pursuit and a short-term action. Some other conceptualizations by the patients could be seen as a disconnection, such as a disconnection in the actor: There seems to be an unexpressed conviction that one actor could die and another one would experience the provided relief (disconnection between the world of agency and the world of experience). Some patients were also ignoring the hierarchy of long-term processes indicating a further action distortion.

The suicidal clients reported on a number of different processes involved in the action of killing oneself, including disengaging memory processes and not monitoring of action, dissociating from the suicide goal (letting it happen), not considering alternatives or inhibiting adequate action and other distortions of action systems or suppressing perpetrator's thoughts. By some, the action to kill oneself was related to the goal of dying, held as given and undisputed, and no further consequences of this action were considered. The processes of regulation, control and steering were severely restricted indicating a distorted action. 
The distortion of action processes was also visible in the experience of being killed (representing the victim), i.e. some persons claimed that they were in a state of trance and did not experience anything. Others were even unconscious or do not remember anything. Some patients were conscious and experiencing, but did not feel any pain when hurting themselves. Many others reported on their thoughts, feelings, and sensations during their actions. Some of these thoughts, feelings, and sensations led the participants to seek help, to plea as a victim to themselves as a perpetrator, while others indicated a disconnection in goals and actions, i.e. a dissociation [35]. Although we suggested that suicide processes are complex goal-directed processes of actions, projects, and career, we also pointed out the merging of the top-down and bottom-up processes in suicidality [36].

When proposing a possible usefulness of neuro-rehabilitation for secondary suicide prevention, it is necessary not only to describe suicide in terms of action, but also to indicate some links to neurological processes $[37,38]$ as is usually the case in neuro-rehabilitation. We were able to indicate in an fMRI study some of the neurological processes associated with the suicide processes [39]. This helped us to better understand the art of distortion of the suicide action [40] and supported our stressing of the processes in suicide as an action and not as a behavior caused by external and structurally defined factors. It has been suggested, that "(n)euroimaging has begun to yield data about structural and functional abnormalities observed in suicidal individuals. Some of the abnormalities, such as structural and functional deficits in prefrontal and limbic areas match up with clinical observation of suicidal patients, who often show poor emotional regulation, impaired decision making, and limited impulse control." [41]. These findings were also supported by the structural analysis of the suicidal brain [42].

Thus, in our research and writings we indicated that suicidality could be understood in terms of goal-directed actions instead of mental health illnesses and disorders such as depression. As the neuro-rehabilitation indicated that body movements in rehabilitation have to be accompanied by cognitive processes to make the desired action complete and the effects of neuro-rehabilitation more sustainable, we suggest that the psychotherapy of suicidality, involving specific action processes has to be accompanied by direct feedback and feed-forward of these action processes. We believe to nurture this by the video self-confrontation interview technique und by inserting the newly learned appropriate strategies during the video self-confrontation as the appropriate action alternatives. With additional technique such as therapeutic alliance, building a trustworthy joint action frame, and a long term on-going contact by letters supporting the long-term frame of the life-enhancing and life-saving project and career we were able to provide an effective secondary suicide prevention in reducing the rates of suicide attempts by $80 \%$ [43].

\section{Psychotherapy in Secondary Suicide Prevention}

There are many psychotherapy approaches and techniques applied in the secondary suicide prevention [44]. Some are linked to a sophisticated theoretical reasoning [45], others were adopted on pragmatic grounds by experienced practitioners [46], often by professionals with personal experience of suicidality, thus offering a deep personal insight into suicide processes $[47,48]$. The scientists as well as the artists among the secondary suicide prevention professionals stress the important role of the relationship in the treatment of such clients and patients [49]. Despite the general recognition of the relevance of therapeutic alliance this is often overlooked in the routine hospital treatment where many patients after a suicide attempt should receive decisive and substantial help to survive their suicide projects [50]. Consequently, a constant reminder of these processes is always needed. The action theory [51] 
informed approach to secondary suicide prevention also explicates in conceptual terms the relevance of establishing a good alliance as launching a joint goal-directed life-enhancing project.

With the action theory conceptualization of suicide processes in mind we can point out the gaps that specific approaches to secondary suicide prevention leave open. The focus of the specific theories and approaches to treatment is also their weakness. The psychodynamic approaches often ignore the cognitive-behavioral organization of the suicide processes and the cardinal role that goal-directed action plays in suicide and life-enhancing process. The cognitive-behavioral approach often assumes the role of top-down cognitive steering in psychotherapy and underestimates the role of practicing in vivo, as well as the integrated nature of action [52] in which inner, manifest and social processes are connected [53], as action theory indicates [54]. Many approaches being scientifically driven are caught in a causal frame that does not allow them to see the goal-directedness of suicide processes, on the one hand, and of the therapy processes, on the other $[55,56]$. Experiential-emotion approaches, although using the experiential nature of healing, often overlook the goal-directedness of the suicide and life-enhancing processes [57]. The conceptualization of bond, task, and goal is reserved for the therapy process [46]. They all have in common a limitation of the procedure of classical "talking cure". On the other hand, the behavioral branch of psychotherapy, including cognitive-behavior therapy suffers under the dualism of inner and manifest processes which contemporary cognitive psychology and neuropsychology render obsolete [58-61]. The duality or division between behavior and cognition has been questioned. Enacted cognition, cognitive neuro-rehabilitation, integrating cognitive and behavioral processes, are all indications thereof. With the reconsideration of the cognition-behavior link or division the tradition of psychotherapy and neuro-rehabilitation are revised. Calling for comprehensive treatment plans for suicidal patients including psychological, as well as biological interventions opens a door for this view [49]. It has been suggested that motivational interventions to improve health behaviors, including suicide prevention, based on conventional cognitive and behavioral theories have been extensively studied. However, advances in neuroimaging technology make it possible to assess the neurophysiological basis of health behaviors and to support new interventions to achieve optimal outcomes [62].

\section{Procedure of Secondary Suicide Prevention Proposed in the Action Theory Informed Approach}

Michel and colleagues [63] developed a secondary suicide prevention procedure based on and expanding the known successful techniques that could answer the needs of hospitals for a brief therapy dealing with patients injured by a suicide attempt. The framework for this procedure [43] was informed by the action theory conceptualization of suicide [34]. The following paragraph summarizes some of the general principles in which the preventive procedure [4] is rooted:

Suicide is seen as a goal-directed process of actions, projects and career. The secondary suicide prevention treatment is also conceptualized as a joint goal-directed process of actions and projects. This process is seen as an integration of subjective, manifest, and social processes. Equally, the action theory informed research perspective employs systematic observation, self-confrontation interviews generating data on subjective processes, and naïve observation providing data on social meaning of these processes. Thus, such data can be included in any research study of suicide processes. The goal-directed processes are seen as systemic processes consisting of a hierarchy encompassing conscious and non-conscious processes and sequence of the action organization - mirroring its 
process nature. Equally, the systemic organization integrates the steering, controlling, and regulating of action. Secondary suicide prevention reflects these issues in many instances. The suicide prevention intervention must be organized in a joint goal-directed project and action. The target of generating a good therapeutic alliance serves this purpose. In addition, the written reminders of the ongoing life-enhancing project serve to maintain this project.

The relying on the clients' narrative reflects the belief that the clients are the most competent authors of such a narrative Michel et al. [50] and the goal-directed stance in that the suicide narrative is presented by the patient reflects the proposed conceptualization of suicide as goal-directed. The support the therapist provides with generating the suicide narrative serves the subjective meaningful view of the client and not the accuracy in regards to structurally defined data, such as time and metrical description of the location of the suicide actions. Another influential procedure is the video self-confrontation interview. It serves several purposes. In the view of the data and information collection it provides information on the subjective processes during both actions - the narrative actions and the suicide actions. In the view of the impact of this procedure and its changing the suicidality there are several points to stress. The main point is experiencing the suicide action in a different emotional, cognitive and action context in seeing oneself telling the suicide story and developing the suicide narrative together with the psychotherapist. Being confronted with the visual representation of the suicide narrative provides information to the patients beyond the described experience. We know that such a visual experience utilizes more than what is formulated in the language.

\section{The Neuro-Rehabilitation Nature of Some of the Outlined Secondary Suicide Prevention Procedures}

The majority of the secondary suicide prevention procedures informed by the action theory could be viewed as occurring in the traditional psychotherapy or "talking cure" setting. However, we would like to stress that some of the principles, such as repeated experiencing of the suicide action (within a suicide narrative and in the video selfconfrontation) or experiencing an inserted alternative course of action in the critical action nodes instead of learning to apply these strategies in a top-down manner go beyond the traditional psychotherapy. Further, the whole suicide prevention process or development the life-enhancing projects including safe life-enhancing action in crisis moments in a performative-experiential manner reminds us more of a rehabilitation exercise than of the classical psychotherapy procedure. We maintain that the action presented in a narrative and experienced in the video selfconfrontation will be "repaired" in an experiential manner when being observed in a different context. Additionally, the experience is repaired in a conscious manner when offered an alternative course of action in times of crisis, as well as inserting these action steps in the video recorded narrative of the suicide action. As the experience during the video self-confrontation is related to specific action segments and not to comprehensive behavioral units that are mostly summarized in a judgmental way it is possible for the patient to stay open minded and prevent a defensive stance that hinders the necessary revising of the action. In repeated engaging in the step-by-step unfolding of the suicide action and project the procedure reminds us of some neuro-rehabilitation procedures.

An analogy can be seen in Constraint-induced movement therapy (CIMT) for upper extremity paresis, whereby the therapy consists of intensive, experience-based, repetitive motor training of a paretic limb [64]. Thus, competent, symmetric movements are restored by immobilizing the unaffected forelimb. Confronting the suicidal patients with 
the video recording of their narrative of suicide action and projects and having the patient replace the suicidal steps by life-enhancing steps could be compared to the procedure of constrain-induced movement therapy. Another analogy is constraint-induced language therapy: researchers proposed that intensive oral communication would promote speech output and language recovery. Equally, intensive immerging into the suicide narrative, further intensified by self-confrontation and corrected by the replacement of the suicide steps by life-enhancing steps can employ similar principles as the constraint-induced language therapy.

Optical displacement by wearing wedge prisms induces a "virtual" mismatch between perception and action, prompting functional, automatic self-corrections. Equally, the self-confrontation induces a mismatch between action situation and perception of action, i.e. the mismatch between action the patients experience on video and the action situation of the secure interview. Using the self-confrontation procedure with its switch of perspectives (from actor to perceiver) might be comparable to the optical change. It has been suggested that virtual reality treatment may bypass a top-down set of didactic, such as verbal instructions common in therapy [21].

The studied secondary suicide prevention procedure [4] could be summarized as follows:

\subsection{Establishing and maintaining a joint project (life enhancing, surviving etc.)}

The person has to engage in a joint project with the aim of survival (to distinguish from the relationship in which the threat of suicide proves to be a means of relationship management). The therapist listens empathically and with full attention to the suicide story, thus generating a good therapeutic alliance.

Project maintenance: patients receive postcards reminding them of this relationship and the joint venture, as well as of the alternative action means.

\subsection{Revising the suicide action}

Video supported recall of the suicide process narrative (i.e. the self-confrontation-interview):

Client or patient reports in brief segments on thoughts and emotions (too short for summarizing judgements), thus reviewing the suicide goal-directed process without judging.

The patient obtains a better insight of the inner processes and experiences the suicide process in a different context (social, emotional, physical, cognitive, action).

The patient experiences the effects of their "own action attention" or self-attention or awareness [65] leading to thepatient experiencing exposure.

\subsection{Joint definition of the critical points of the suicide processes}

The action theory suggests that critical or difficult nodes in the action sequence require increased attention. Joint generation of the alternative functional ways for survival and life enhancement. Written documentation of these alternatives serve as an external reminder in the moment of the cognitive-emotional overflow or crisis. Brief practice of recognizing the critical nods and using of the alternative means (second viewing of the narratives). Reminding the patient about the joint life-enhancing project by written postal notes (letters). 


\section{Conclusion}

We highlighted some suggestions in the recent conceptualizing of suicide processes that the suicide process should be seen in its specific idiosyncratic form, which differs from many forms of psychopathology as codified in DSM or ICD classifications. The close link with action processes as formulated in some psychological and neurological theories and research studies motivated us to examine how neurological problems are treated in other health services, such as neuro-rehabilitation in contrast to psychotherapy. We argued that some of the procedures suggested and applied in the action theory informed study by Michel and colleagues [63] can be compared in their impact to neuro-rehabilitation procedures. In suggesting this comparison we hope to inspire others to integrate more of the brain training techniques when the neurological roots of behavioral problems are studied. It also could be instructional to acknowledge how the issue of intentionality [66] has been integrated in the neuro-rehabilitation [64]. Psychotherapy and neuro-rehabilitation are two distinctive traditions of changing human behavior. With the recent growth in research in neurosciences we now know more about the neurological changes during and following psychotherapy $[67,68]$, thus enlarging and improving our understanding of the neurological base of psychotherapy. We are also more able to compare these contributions to the changes achieved in neuro-rehabilitation.

\section{References}

1. Buxbaum LJ. Complex object-related actions: Structure, meaning, and context. Journal of the International Neuropsychological Society 13 (2007): 993-996.

2. Rosenbaum DA. The Cinderella of psychology: The neglect of motor control in the science of mental life and behavior. American Psychology 60 (2005): 308-317.

3. Frith CD, Frith U. The neural basis of mentalizing. Neuron 50 (2006): 531-534.

4. Michel K, Gysin-Maillart A. ASSIP - Attempted Suicide Short Intervention Program: A Manual for Clinicians. Goettingen: Hogrefe Publishing (2015).

5. Bender A, Adrion C, Fischer L, et al. Long-term rehabilitation in patients with acquired brain injury: A randomized controlled trial of an intensive, participation-focused outpatient treatment program. Deutsches Ärzteblatt International 113 (2016): 634-641.

6. Martínez-Pernía D, González-Castán Ó, Huepe D. From ancient Greece to the cognitive revolution: A comprehensive view of physical rehabilitation sciences. Physiother Theory Pract 33 (2017): 89-102.

7. Brands I, Stapert S, Köhler S, et al. Life goal attainment in the adaptation process after acquired brain injury: The influence of self-efficacy and of flexibility and tenacity in goal pursuit. Clinical Rehabilitation 29 (2015): 611-622.

8. Castellanos NP, Rodríguez-Toscano E, García-Pacios J, et al. Traumatic brain injury: Neuropsychological rehabilitation. In G. Leisman \& J. Merrick (Eds), Neuroplasticity in learning and rehabilitation. Hauppauge, NY, US: Nova Biomedical Books (2016): 121-131.

9. Wilson BA. Neuropsychological rehabilitation. Annual Review of Clinical Psychology 4 (2008): 141-162.

10. Hartmann K, Goldenberg G, Daumüller M, et al. It takes the whole brain to make a cup of coffee: The neuropsychology of naturalistic actions involving technical devices. Neuropsychologia 43 (2005): 625-637.

11. Jeannerod M. Fundamentals of cognitive neuroscience. The cognitive neuroscience of action. Malden: Blackwell Publishing (1997). 
12. Vingerhoets G, Harrington D. Introduction to the JINS special issue: Motor cognition. Journal of the International Neuropsychological Society 23 (2017): 103-107.

13. Barrett AM, Oh-Park M, Chen P, et al. Neurorehabilitation. Five new things. Neurol Clin Pract 3 (2013): 484-492.

14. Meichenbaum DH. Cognitive behavior modification: An integrative approach. New York: Plenum (1977).

15. Martínez-Pernía D, Huepe D, Huepe-Artigas D, et al. Enactive approach and dual-tasks for the treatment of severe behavioral and cognitive impairment in a person with acquired brain injury: A case study. Frontiers in Psychology 7 (2016): 1712.

16. Heuninckx S, Wenderoth N, Debaere F, et al. Neural basis of aging: the penetration of cognition into action control. The Journal of Neuroscience 25 (2005): 6787-6796.

17. McDowd JM, Filion DL, Pohl PS, et al. Attentional abilities and functional outcomes following stroke. The Journals of Gerontology. Series B: Psychological Sciences and Social Sciences 58 (2003): 45.

18. Johansen-Berg H, Duzel E. Neuroplasticity: Effects of Physical and Cognitive activity on brain structure and function. NeuroImage 131 (2016): 1-3.

19. Shaffer J. Neuroplasticity and clinical practice: Building brain power for health. Frontiers in Psychology 7 (2016): 1118.

20. Constans A, Pin-barre C, Temprado J-J, et al. Influence of aerobic training and combinations of interventions on cognition and neuroplasticity after stroke. Frontiers in Aging Neuroscience 8 (2016): 164.

21. Bryck RL, Fisher PA. Training the brain. American Psychologist 67 (2012): 87-100.

22. Teo W-P, Muthalib M, Yamin S, et al. Does a combination of virtual reality, neuromodulation and neuroimaging provide a comprehensive platform for neurorehabilitation? A narrative review of the literature. Frontiers in Human Neuroscience 10 (2016): 284.

23. Oostra KM, Oomen A, Vanderstraeten G, et al. Influence of motor imagery training on gait rehabilitation in sub-acute stroke: A randomized controlled trial. Journal of Rehabilitation Medicine 47 (2015): 204-209.

24. Chung CSY, Pollock A, Campbell T, et al. Cognitive rehabilitation for executive dysfunction in adults with stroke or other adult non-progressive acquired brain damage. Cochrane Database of Systematic Reviews 4. Art. No.: CD008391 (2013).

25. Dymowski AR, Ponsford JL, Willmott C. Cognitive training approaches to remediate attention and executive dysfunction after traumatic brain injury: A single-case series. Neuropsychological Rehabilitation 26 (2016): 866-894.

26. Rohling ML, Faust ME, Beverly B, et al. Effectiveness of cognitive rehabilitation following acquired brain injury: A meta-analytic re-examination of Cicerone et al.'s (2000, 2005). Systematic reviews. Neuropsychology 23 (2009): 20-39.

27. Seitz RJ, Binkofski F, Freund HJ. Motor dysfunction and recovery. In: J., Bogousslavsky (Ed.), Long-term effects of stroke New York: Marcel Dekker (2002): 105-147.

28. Garza MA, Wason EA, Zhang JQ. Cardiac remodelling and physical training post myocardial infarction. World J Cardiol 7 (2015): 52-64.

29. Morris DM, Bickel CS. Activity-based interventions for neuro-rehabilitation. In S. A. Raskin (Ed.), Neuroplasticity and rehabilitation. New York: Guilford Press (2011): 117-148. 
30. Pompili M, Venturini P, Lamis DA, et al. Suicide in stroke survivors: Epidemiology and prevention. Drugs and Aging 32 (2015): 21-29.

31. Nock MK. (Ed.) The Oxford handbook of suicide and self-injury. Oxford: Oxford University Press (2014).

32. O'Connor RC, Pirkis J. The international handbook of suicide prevention. Chichester: Wiley (2016).

33. Celano CM, Beale EE, Mastromauro CA, et al. Psychological interventions to reduce suicidality in highrisk patients with major depression: A randomized controlled trial. Psychological Medicine 23 (2016).

34. Michel K, Valach L. Suicide as goal-directed action. In Ed. K. van Heeringen (Ed.), Understanding Suicidal Behaviour: the Suicidal Process Approach to Research and Treatment. Chichester: Wiley \& Sons (2002): 230-254.

35. Valach L, Michel K, Young RA. Suicide as a distorted goal-directed process: Wanting to die, killing, and being killed. J Nerv Ment Dis 204 (2016): 812-819.

36. Valach L, Michel K, Young RA, et al. Linking life and suicide related goal directed systems. Journal of Mental Health Counseling 28 (2006): 353-372.

37. Keilp JG, Sackeim HA, Brodsky BS, et al. Neuropsychological dysfunction in depressed suicide attempters. Am J Psychiatry 158 (2001): 735-741.

38. Michel K, Jobes DA. Building a therapeutic alliance with the suicidal patient. Washington DC: American Psychological Association (2011).

39. Reisch T, Seifritz E, Esposito F, et al. An fMRI study on mental pain and suicidal behavior. Journal of Affective Disorders 126 (2010): 321-325.

40. Michel K. Will new insights into neural networks help us improve our models of suicidal behavior? Crisis, 35 (2014): 215-218.

41. Sudol K, Oquendo MA. Visualizing the suicidal brain: Neuroimaging and suicide prevention. In R. C. O’Connor \& J. Pirkis (Eds.), The international handbook of suicide prevention. Chichester: John Wiley (2016): 188-205.

42. Gosnell SN, Velasquez KM, Molfese DL, et al. Prefrontal cortex, temporal cortex, and hippocampus volume are affected in suicidal psychiatric patients. Psychiatry Research: Neuroimaging 256 (2016): 50-56.

43. Michel K, Valach L, Gysin-Maillart A. A novel therapy for people who attempt suicide and why we need new models of suicide. Int. J. Environ. Res. Public Health 14 (2017): 243.

44. van Heeringen EK. Understanding suicidal behaviour: the suicidal process approach to research and treatment. Chichester: Wiley and Sons (2002).

45. O'Connor RC, Cleare S, Eschle S, et al. The integrated motivational-volitional model of suicidal behavior. In R. C. O'Connor and J. Pirkis (Eds.). The international handbook of suicide prevention. Chichester: Wiley (2016): 220-240.

46. Greenberg LS, Rice LN, Elliott R. Facilitating emotional change. New York: The Guilford Press (1993).

47. Joiner T. Why people die by suicide. Cambridge, MA: Harvard University Press (2005).

48. Linehan MM. DBT skills training manual. New York: Guilford Press (2014).

49. Michel K. Neurobiology and patient-oriented models of suicide - a contradiction? In K. Michel, \& D. A. Jobes (Eds.), Building a therapeutic alliance with the suicidal patient. Washington DC: American Psychological Association (2011): 183-201. 
50. Michel K, Valach L. The narrative interview with the suicidal patient. In K. Michel and D. A. Jobes, (Eds.). Building a therapeutic alliance with the suicidal patient. Washington DC: American Psychological Association (2011): 63-80.

51. Valach L, Young RA, Lynam MJ. Action theory. A primer for applied research in the social sciences. Westport, CT: Praeger (2002).

52. Ellis TE. Cognition and suicide. Washington: American Psychological Association (2006).

53. Cranach M. von, Kalbermatten U. Ordinary interactive action: theory, methods and some empirical findings. In M. von Cranach \& R. Harré. The analysis of action: Recent theoretical and empirical advances. Cambridge: Cambridge University Press (1982): 115-160.

54. Valach L, Young RA. Suicide and counseling for suicidality. In R. A. Young, J. F. Domene, \& L. Valach, (Eds.), Counseling and action. Toward life-enhancing work, relationship, and identity New York: Springer (2015): 295-313.

55. van Heeringen K. Toward a psychobiological model of the suicidal processes. In K. van Heeringen (Ed.). Understanding suicidal behavior. Chichester: Wiley (2001): 136-159.

56. van Heeringen K, Bijttebier S. Understanding the suicidal brain. In R. C. O’Connor \& J. Pirkis (Eds.). The international handbook of suicide prevention. Chichester: Wiley (2016): 170-187.

57. Greenberg L. Emotion-focused therapy: Theory and practice. Washington, DC: American Psychological Association (2010).

58. Frisina WG. The unity of knowledge and action. Albany, NY: New York University Press (2002).

59. Noë A. Action in perception. Cambridge, MA: The MIT Press (2004).

60. Prinz W, Beisert M, Herwig A. Action science. Cambridge, MA: The MIT Press (2013).

61. Stewart J, Gapenne O, Di Paolo EA. Enaction. Cambridge, MA: The MIT Press (2010).

62. Bosak K, Martin L. Neuroimaging of goal-directed behavior in midlife women. Nursing Research 63: (2014): 388-396.

63. Gysin-Maillart A, Schwab S, Soravia L, et al. A novel brief therapy for patients who attempt suicide: A 24months follow-up randomized controlled study of the attempted suicide short intervention program (ASSIP). PLoS Med 13 (2016): e1001968.

64. Pomeroy V, Aglioti SM, Mark VW, et al. Neurological principles and rehabilitation of action disorders: Rehabilitation interventions. Neurorehabil Neural Repair 25 (2011): 33S-43S.

65. Carver CS. Self-awareness. In Leary MR, Tangney JP. Handbook of self and identity (2nd Edn.) New York, NY, US: Guilford Press (2012): 50-68.

66. Leisman G, Machado G, Melillo R, et al. Intentionality and "free-will" from a neurodevelopmental perspective. Frontiers in Integrative Neuroscience 6 (2012): 1-12.

67. Grawe K. Neuropsychotherapy: How the neurosciences inform effective psychotherapy. Mahwah NJ: Lawrence Erlbaum Associates (2007).

68. Ivey AE, Zalaquett CP. Neuroscience and Counseling: Central Issue for Social Justice Leaders. Journal for Social Action in Counseling and Psychology 3 (2011): 103-116. 